\title{
Erratum zu: Relevanz schulischer Medienkonzepte als Orientierung für die Schule im Zuge der fortschreitenden Digitalisierung
}

\author{
Melanie Heldt • Ramona Lorenz iD $\cdot$ Birgit Eickelmann
}

Online publiziert: 11 . August 2021

(C) Der/die Autor(en) 2021

\section{Erratum zu:}

\section{Unterrichtswiss 2020}

https://doi.org/10.1007/s42010-020-00070-y

Der Artikel Relevanz schulischer Medienkonzepte als Orientierung für die Schule im Zuge der fortschreitenden Digitalisierung von Melanie Heldt, Ramona Lorenz und Birgit Eickelmann wurde ursprünglich Online First ohne „Open Access“ auf der Internetplattform des Verlags publiziert. Nach der Veröffentlichung in Bd. 48 Heft 3 pp. 447-468 hatten sich der Autor für eine „Open Access“-Veröffentlichung entschieden. Das Urheberrecht des Artikels wurde deshalb in () Der/die Autor(en) 2021 geändert. Dieser Artikel ist jetzt unter der Creative Commons Namensnennung 4.0 International Lizenz veröffentlicht, welche die Nutzung, Vervielfältigung, Bearbeitung, Verbreitung und Wiedergabe in jeglichem Medium und Format erlaubt, sofern Sie den/die ursprünglichen Autor(en) und die Quelle ordnungsgemäß nennen, einen Link zur Creative Commons Lizenz beifügen und angeben, ob Änderungen vorgenommen wurden.

Die Online-Version des Originalartikels ist unter https://doi.org/10.1007/s42010-020-00070-y zu finden.

Melanie Heldt $(\varangle) \cdot$ Birgit Eickelmann Institut für Erziehungswissenschaft, Lehrstuhl für Schulpädagogik, Universität Paderborn, Warburger Str. 100, 33098 Paderborn, Deutschland

E-Mail: melanie.heldt@uni-paderborn.de

Birgit Eickelmann

E-Mail: birgit.eickelmann@upb.de

Ramona Lorenz

Institut für Schulentwicklungsforschung, Technische Universität Dortmund,

Vogelpothsweg 78, 44227 Dortmund, Deutschland

E-Mail: ramona.lorenz@tu-dortmund.de 
Die in diesem Artikel enthaltenen Bilder und sonstiges Drittmaterial unterliegen ebenfalls der genannten Creative Commons Lizenz, sofern sich aus der Abbildungslegende nichts anderes ergibt. Sofern das betreffende Material nicht unter der genannten Creative Commons Lizenz steht und die betreffende Handlung nicht nach gesetzlichen Vorschriften erlaubt ist, ist für die oben aufgeführten Weiterverwendungen des Materials die Einwilligung des jeweiligen Rechteinhabers einzuholen.

Funding Open Access funding enabled and organized by Projekt DEAL.

Open Access Dieser Artikel wird unter der Creative Commons Namensnennung 4.0 International Lizenz veröffentlicht, welche die Nutzung, Vervielfältigung, Bearbeitung, Verbreitung und Wiedergabe in jeglichem Medium und Format erlaubt, sofern Sie den/die ursprünglichen Autor(en) und die Quelle ordnungsgemäß nennen, einen Link zur Creative Commons Lizenz beifügen und angeben, ob Änderungen vorgenommen wurden.

Die in diesem Artikel enthaltenen Bilder und sonstiges Drittmaterial unterliegen ebenfalls der genannten Creative Commons Lizenz, sofern sich aus der Abbildungslegende nichts anderes ergibt. Sofern das betreffende Material nicht unter der genannten Creative Commons Lizenz steht und die betreffende Handlung nicht nach gesetzlichen Vorschriften erlaubt ist, ist für die oben aufgeführten Weiterverwendungen des Materials die Einwilligung des jeweiligen Rechteinhabers einzuholen.

Weitere Details zur Lizenz entnehmen Sie bitte der Lizenzinformation auf http://creativecommons.org/ licenses/by/4.0/deed.de. 